\title{
An Empirical Assessment of Shared Understanding in IT Governance Implementation
}

\author{
Anant Joshi \\ Maastricht University, \\ Maastricht, The Netherlands \\ A.joshi@maastrichtuniversity.nl \\ Steven De Haes \\ University of Antwerp, \\ Antwerp, Belgium \\ Steven.dehaes@uantwerpen.be
}

\author{
Tim Huygh \\ University of Antwerp, \\ Antwerp, Belgium \\ Tim.huygh@uantwerpen.be \\ Wim Van Grembergen \\ University of Antwerp, \\ Antwerp, Belgium \\ Wim.vangrembergen@uantwerpen.be
}

\begin{abstract}
Drawing on literature about social alignment and shared understanding between different internal stakeholders, this study sets out to analyze the association between stakeholder functional role and the perceived level of IT governance implementation. Specifically, this paper takes a COBIT 5 perspective, by first analyzing perception differences at the level of the implementation of the seven COBIT 5 enablers, followed by an analysis at the level of the five COBIT 5 process domains. The results indicate that shared understanding about the IT governance implementation level between different organizational stakeholders can be improved, especially between (1) IT and (2) audit, risk, and compliance (ARC) stakeholders.
\end{abstract}

\section{Introduction}

In an increasingly digitized economy, organizational decision-makers are more and more confronted with the pervasiveness of IT. Investments in IT form a large portion of total investments for many contemporary organizations. For this reason, a focus on the governance and management of IT is warranted, to ensure that the current and future investments in IT are in line with business needs, and all of this at a level of IT-related risk that is appropriate for the organization [1].

Academic research has provided answers on how organizations can implement IT governance. The stateof-the-art view in academia is that IT governance should be implemented as a holistic set of structures, processes, and relational mechanisms [1]-[7]. From the practitioner area, guidance has also surfaced. The leading practitioner framework for the governance and management of enterprise IT is developed by ISACA.
The framework is called COBIT (Control Objectives for Information and Related Technologies), and is currently in its fifth edition (www.isaca.org/COBIT).

In the realm of shared understanding between different types of stakeholders in an organization, the question can be asked whether these different stakeholders evaluate the implementation level of the governance and management of IT mechanisms in a similar fashion. Higher levels of shared understanding in this area imply that the key stakeholders in the firm have a great degree of synergy when it comes to their understanding of the implementation of a suitable IT governance framework. This in turn can help organizations to realize the benefits of IT governance in a more consistent way with the desired business goals. This paper sets out to research the effect of functional role on the perceived IT governance implementation level by focusing on three relevant stakeholder groups in the area of IT governance: (1) business, (2) IT, and (3) audit, risk, and compliance. Thus, the level of granularity of analysis in this paper is limited to these three different groups as collectives (i.e. business functional units are not further separated during analysis). Therefore, this paper puts forward the following research question: "How do (1) business, (2) IT, and (3) audit, risk, and compliance stakeholders evaluate the implementation level of IT governance mechanisms?"

The results of this analysis will then provide insights in the state of shared understanding between these three relevant stakeholder groups in the area of enterprise governance and management of IT, and specifically in perceptions regarding the state of IT governance implementation. This research can be seen as a first step in the quest through the puzzle of shared understanding about enterprise governance and management of IT. 
Also, while most of the traditional strategic alignment literature mainly includes IT and business functions, we incorporate the audit, risk, and compliance function to shed more enriched insights on the discussion of shared understanding in IT governance implementation.

\section{Theoretical background}

\subsection{Social alignment and the need for shared understanding}

Following Henderson \& Venkatraman [8], the alignment between business and IT is seen as the continuous process of aligning four components: business strategy, IT strategy, organizational infrastructure and processes, and IT infrastructure and processes. Later, authors referred to this view on alignment as the "intellectual dimension" of business/IT alignment [9]. Next to this "intellectual dimension”, it is acknowledged that there also should be a shared understanding among internal stakeholders about these four components that need to be aligned, which was then referred to as the "social dimension" of business/IT alignment [9]. Building on these ideas, scholars then found shared understanding between business and IT executives to be a key antecedent of strategic alignment [10]. This shared understanding was found to be influenced by a shared language and shared domain knowledge between business and IT. When business and IT executives communicate in formal organizational structures (e.g. IT governance structural mechanisms), the shared understanding between them will increase, ultimately leading to more effective IT governance [10], [11]. Shared understanding between business and IT is therefore important to achieve, as it helps IT people to see how IT is applicable to solve business problems [9], [12], [13]. In this paper, we propose to extend this logic to shared understanding about the governance and management of IT. By doing so, we examine how the existing knowledge of three stakeholder groups (i.e. business; IT; and audit, risk, and compliance) regarding IT practices can foster or impede IT governance implementation.

\subsection{IT governance and the COBIT 5 framework}

Enterprise governance of IT (EGIT), or mainly referred to as 'IT governance' is an integral part of corporate governance, with a focus on IT-related (digital) assets

\footnotetext{
${ }^{1}$ For brevity, we do not provide a detailed discussion on each of the enablers. However, a detailed description of COBIT 5 enablers is available through the COBIT 5 framework.
}

[3]. The primary focus of IT governance is to establish structures, processes, and relational mechanisms to govern IT assets, thereby achieving strong business/IT alignment, and ultimately improving the return on ITenabled investments [1]. Consistent with this scope, De Haes \& Van Grembergen [14, p. 3] define enterprise governance of IT as "an integral part of corporate governance [that] addresses the definition and implementation of processes, structures and relational mechanisms in the organization that enable both business and IT people to execute their responsibilities in support of business/IT alignment and the creation of business value from IT-enabled business investments.”

Over the past two decades, scholars have examined how organizations can implement IT governance (e.g. [2][7]) and how the governance of IT can improve firm performance (e.g. [15]-[17]). However, successful implementation of IT governance is complex and warrants robust guidelines that can help firms in developing effective and efficient structures, processes, and relational mechanisms to govern IT. In this context, extant literature has shown a significant role of best practice-based IT governance frameworks and standards in implementing effective IT governance practices [18]. In the practitioner area, undoubtedly the most extensive framework that can be used as a toolkit for enterprise governance and management of IT is Control Objectives in Information and Related Technologies (COBIT), developed by ISACA [19]. This framework is currently in its fifth edition and is centered around seven enablers for the governance and management of IT, which are interconnected, and should all be considered when implementing IT governance. Enablers in COBIT 5 are defined as: “[...] factors that, individually and collectively, influence whether something will work - in this case, governance and management of enterprise IT" [19]. The following seven enablers are part of COBIT 5: Principles, policies and frameworks (eg. acceptable use policies); processes (eg. portfolio management); organizational structures (eg. IT steering committees); culture, ethics and behavior (eg. tone at the top); information (eg. quality of the IT strategy document); services, infrastructure and applications (eg. tools to support the project management process); and people, skills and competencies (eg. skill set of the CIO) ${ }^{1}$.

This research first analyses the seven enablers in general, after which it focuses on the process enabler ${ }^{2}$,

\footnotetext{
${ }^{2}$ More specifically, this research focuses in the second stage on the five process domains (operationalized as averages of the processes that belong to those domains). This choice was made due to space
} 
as this enabler guide is currently fully developed as part of the COBIT 5 product suite (as the result of a long history of COBIT processes development). COBIT identifies 37 processes spread over one governance and four management domains. The governance domain covers processes that are the board's responsibilities in IT (e.g. risk appetite). In the management area, four domains of processes are defined: Align, Plan, Organise (APO), Build, Acquire and Implement (BAI), Deliver, Service and Support (DSS) and Monitor, Evaluate and Assess (MEA).

Prior academic research also indicates that processes are the most important IT governance mechanisms, as well as perceived to be the most difficult to implement [2]. As these processes prove difficult to implement, it might also be that there are differences in the perceptions that different stakeholder groups have on their implementation level.

\subsection{Conceptual model}

Research on shared understanding has remained almost entirely in the area of business/IT alignment. However, we propose that shared understanding should also be achieved in the area of IT governance, which is seen as a critical antecedent for achieving business/IT alignment [1], [15]. Therefore, the aim of this paper at the conceptual level is to analyze the effect of functional role on perceived IT governance implementation level. This dependent construct is operationalized through COBIT 5 (i.e. the enablers in the first stage of the research and the process domains in the second stage of the research). The independent (grouping) variable is operationalized by means of a categorical variable with the following three categories, which each represent a relevant stakeholder group in the area of enterprise governance and management of IT: (1) business, (2) IT, and (3) audit, risk, and compliance. The conceptual model and operationalization driving this research is presented by means of Figure 1.

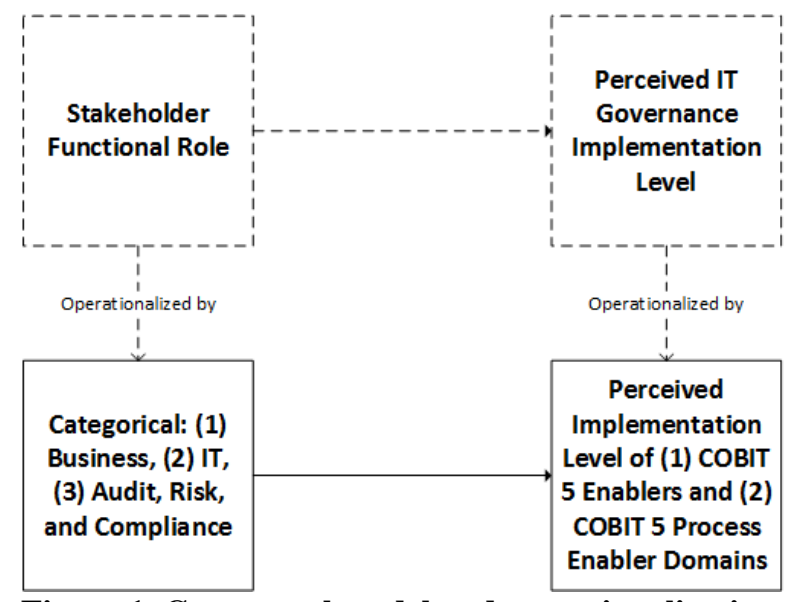

Figure 1. Conceptual model and operationalization

\section{Research methodology}

\subsection{Sample}

The dataset for this research project was collected through an online survey between $24^{\text {th }}$ of July and $1^{\text {st }}$ of September, 2014. Business, IT, and audit representatives were solicited through local ISACA chapters. All descriptions provided in the survey were based on COBIT 5, but expressed in a way that prior knowledge of COBIT 5 was not required. The online survey captured, among other things, the respondents' perceived assessment of the implementation status of the seven COBIT 5 enablers and the 37 COBIT 5 processes. In total 896 respondents completed the survey, of which 881 were accepted as complete responses for the final analysis.

Over the following tables, we present some sample demographics. Table 1 presents the distribution of the respondent functional role in the sample, which is the independent variable (or grouping variable) in this analysis. Table 2 presents the distribution of firm size in the sample. Table 3 shows the distribution of geographical location of the firms in the sample. Finally, Table 4 shows the distribution of IT strategic role in the sample. This classification is based on the firm industry, and is in line with [20]. Automate industries replace human labor by automating business processes (e.g. metal manufacturing), informate industries provide data/information to empower management and employees (e.g. food services), and transform industries fundamentally alter traditional ways of doing business by redefining business processes and relationships (e.g.

limitations, as presenting and discussing the results at the level of the 37 individual COBIT 5 processes was not deemed feasible in the realm of this proceedings paper. 
airlines). In summary, the sample provides a good balance in terms of firm size, geographic location of the firm, and firm IT strategic role.

Table 1. Demographics: Respondent functional role $(\mathrm{N}=\mathbf{8 6 7})$

\begin{tabular}{|l|l|l|}
\cline { 2 - 3 } Business & Frequency & Percent \\
\hline IT risk, and & 59 & 6.7 \\
\hline $\begin{array}{l}\text { Audit, } \\
\text { compliance }\end{array}$ & 394 & 44.7 \\
\hline
\end{tabular}

Table 2. Demographics: Firm size $(\mathrm{N}=\mathbf{8 8 1})$

\begin{tabular}{|l|l|l|}
\cline { 2 - 3 } \multicolumn{1}{c|}{ Frequency } & Percent \\
\hline Fewer than 50 employees & 44 & 5.0 \\
\hline $\mathbf{5 0 - 1 4 9}$ employees & 32 & 3.6 \\
\hline $\mathbf{1 5 0 - 4 9 9}$ employees & 127 & 14.4 \\
\hline $\mathbf{1 , 5 0 0 - 4 , 9 9 9}$ employees & 146 & 16.6 \\
\hline $\mathbf{5 , 0 0 0 - 9 , 9 9 9}$ employees & 108 & 19.8 \\
\hline $\mathbf{1 0 , 0 0 0 - 1 4 , 9 9 9}$ employees & 55 & 12.3 \\
\hline $\mathbf{1 5 , 0 0 0}$ or more employees & 195 & 6.2 \\
\hline
\end{tabular}

Table 3. Demographics: Region of the organization $(\mathrm{N}=\mathbf{8 8 1})$

\begin{tabular}{|l|l|l|}
\cline { 2 - 3 } \multicolumn{1}{c|}{} & \multicolumn{1}{c|}{ Frequency } & \multicolumn{1}{c|}{ Percent } \\
\hline Africa & 81 & 9.2 \\
\hline Asia & 179 & 20.3 \\
\hline Caribbean & 3 & 0.3 \\
\hline $\begin{array}{l}\text { Central } \\
\text { America }\end{array}$ & 6 & 0.7 \\
\hline Europe & 209 & 23.7 \\
\hline Middle East & 50 & 5.7 \\
\hline $\begin{array}{l}\text { North } \\
\text { America }\end{array}$ & 274 & 31.1 \\
\hline Oceania & 27 & 3.1 \\
\hline South America & 52 & 5.9 \\
\hline
\end{tabular}

Table 4. Demographics: Organization IT strategic role $(\mathrm{N}=\mathbf{8 8 1})$

\begin{tabular}{|l|l|l|}
\cline { 2 - 3 } \multicolumn{1}{c|}{ Frequency } & Percent \\
\hline Automate & 165 & 18.7 \\
\hline Informate & 374 & 42.5 \\
\hline Transform & 342 & 38.8 \\
\hline
\end{tabular}

\subsection{Statistical approach}

The research goal of this paper points in the direction of comparing central tendency over the three respondent groups. One-way ANOVA is a statistical test that is used to determine whether group means are different in the population. The one-way ANOVA tests the following null hypothesis: $\mathrm{H}_{0}$ : all group population means are equal (i.e. in our case, $\mu_{1}=\mu_{2}=\mu_{3}$ ). Accordingly, the alternative hypothesis is: $\mathrm{H}_{\mathrm{A}}$ : at least one group population mean is different (i.e., they are not all equal). One of the assumptions of one-way ANOVA is that the dependent variable should be continuous. However, it is common practice to treat ordinal data like ours as continuous, since the scale (i.e. 5-point ordinal from 'not implemented' to 'fully implemented') was constructed to be equidistant. The one-way ANOVA is referred to as an omnibus test, because it does not go into specifics about where the differences between groups lie. To find out which combination of two groups have a significant difference, pairwise comparisons are used (i.e. a comparison between two separate groups). Common post hoc tests test for all possible combinations of these pairwise comparisons. In this paper, Tukey's HSD post hoc tests are used when equality of variances is established, and Games-Howell post hoc tests are used when equality of variances is not established.

\section{Results}

\subsection{COBIT 5 enablers}

\subsubsection{Descriptives}

Table 5 presents descriptive statistics for the seven COBIT 5 enablers over the three functional roles.

Table 5. Descriptive statistics for COBIT 5 enablers over functional roles

\begin{tabular}{|c|c|c|c|c|c|c|c|c|}
\hline & & $\mathbf{N}$ & Mean & $\begin{array}{l}\text { Std. } \\
\text { Dev. }\end{array}$ & $\begin{array}{c}95 \% \text { CI } \\
\text { for mean } \\
\text { (lower) }\end{array}$ & $\begin{array}{c}95 \% \text { CI } \\
\text { for mean } \\
\text { (upper) }\end{array}$ & Min & Max \\
\hline \multirow{5}{*}{ Information } & Business & 59 & 3.68 & 0.880 & 3.45 & 3.91 & 1 & 5 \\
\hline & IT & 390 & 3.57 & 0.929 & 3.47 & 3.66 & 1 & 5 \\
\hline & ARC & 410 & 3.73 & 0.861 & 3.64 & 3.81 & 1 & 5 \\
\hline & Total & 859 & 3.65 & 0.896 & 3.59 & 3.71 & 1 & 5 \\
\hline & Business & 58 & 3.41 & 0.992 & 3.15 & 3.67 & 1 & 5 \\
\hline
\end{tabular}




\begin{tabular}{|c|c|c|c|c|c|c|c|c|}
\hline \multirow{3}{*}{$\begin{array}{l}\text { Principles, } \\
\text { Policies and } \\
\text { Frameworks }\end{array}$} & IT & 393 & 3.36 & 0.996 & 3.27 & 3.46 & 1 & 5 \\
\hline & ARC & 413 & 3.60 & 0.929 & 3.51 & 3.69 & 1 & 5 \\
\hline & Total & 864 & 3.48 & 0.970 & 3.41 & 3.54 & 1 & 5 \\
\hline \multirow{4}{*}{$\begin{array}{l}\text { Culture, } \\
\text { Ethics and } \\
\text { Behavior }\end{array}$} & Business & 58 & 3.55 & 1.046 & 3.28 & 3.83 & 1 & 5 \\
\hline & IT & 392 & 3.29 & 1.085 & 3.18 & 3.40 & 1 & 5 \\
\hline & ARC & 412 & 3.56 & 1.008 & 3.46 & 3.65 & 1 & 5 \\
\hline & Total & 862 & 3.43 & 1.054 & 3.36 & 3.50 & 1 & 5 \\
\hline \multirow{4}{*}{$\begin{array}{l}\text { People, Skills } \\
\text { and } \\
\text { Competencies }\end{array}$} & Business & 58 & 3.71 & 0.838 & 3.49 & 3.93 & 1 & 5 \\
\hline & IT & 394 & 3.57 & 0.958 & 3.47 & 3.66 & 1 & 5 \\
\hline & ARC & 414 & 3.64 & 0.848 & 3.56 & 3.72 & 1 & 5 \\
\hline & Total & 866 & 3.61 & 0.899 & 3.55 & 3.67 & 1 & 5 \\
\hline \multirow{4}{*}{$\begin{array}{l}\text { Services, } \\
\text { Infrastructure } \\
\text { and } \\
\text { Applications }\end{array}$} & Business & 58 & 3.84 & 0.988 & 3.59 & 4.10 & 1 & 5 \\
\hline & IT & 393 & 3.92 & 0.878 & 3.83 & 4.00 & 1 & 5 \\
\hline & ARC & 412 & 3.87 & 0.836 & 3.79 & 3.95 & 1 & 5 \\
\hline & Total & 863 & 3.89 & 0.865 & 3.83 & 3.95 & 1 & 5 \\
\hline \multirow{4}{*}{$\begin{array}{l}\text { Organizational } \\
\text { Structures }\end{array}$} & Business & 58 & 3.79 & 1.005 & 3.53 & 4.06 & 1 & 5 \\
\hline & IT & 392 & 3.62 & 1.024 & 3.52 & 3.72 & 1 & 5 \\
\hline & ARC & 412 & 3.78 & 1.002 & 3.68 & 3.88 & 1 & 5 \\
\hline & Total & 862 & 3.71 & 1.014 & 3.64 & 3.78 & 1 & 5 \\
\hline \multirow[t]{4}{*}{ Processes } & Business & 57 & 3.47 & 0.966 & 3.22 & 3.73 & 1 & 5 \\
\hline & IT & 394 & 3.44 & 0.929 & 3.35 & 3.53 & 1 & 5 \\
\hline & ARC & 412 & 3.63 & 0.880 & 3.55 & 3.72 & 1 & 5 \\
\hline & Total & 863 & 3.53 & 0.912 & 3.47 & 3.59 & 1 & 5 \\
\hline
\end{tabular}

\subsubsection{One-way ANOVA}

First, we test the null hypothesis of equal perceived implementation level between the three stakeholder groups at the level of the seven COBIT 5 enablers. The results of this one-way ANOVA analysis are displayed in Table 6. The Levene test for homogeneity of variances was significant for the information enabler $(\mathrm{p}=0.024)$ and the people, skills and competencies enabler $(p=0.007)$. This means that for these enablers, a robust test of equality of means was used (i.e.
Welch). These robust results are displayed in Table 7. For both tables, significant results are shaded grey. Out of the seven enablers, we find a significant difference for four enablers. This indicates a considerable difference in the perceived level of shared understanding among the three stakeholder groups. A pairwise comparison was conducted to provide more insights on the perceived differences on the implementation of these four enablers.

Table 6. One-way ANOVA results for COBIT 5 enablers (significance level of 0.05 )

\begin{tabular}{|c|c|c|c|c|c|c|}
\hline & & $\begin{array}{l}\text { Sum of } \\
\text { Squares }\end{array}$ & df & $\begin{array}{l}\text { Mean } \\
\text { Square }\end{array}$ & $\mathbf{F}$ & Sig. \\
\hline \multirow{3}{*}{$\begin{array}{l}\text { Principles, } \\
\text { Policies and } \\
\text { Frameworks }\end{array}$} & $\begin{array}{l}\text { Between } \\
\text { groups }\end{array}$ & 11.311 & 2 & 5.655 & 6.084 & 0.002 \\
\hline & $\begin{array}{l}\text { Within } \\
\text { groups }\end{array}$ & 800.314 & 861 & 0.930 & & \\
\hline & Total & 811.625 & 863 & & & \\
\hline \multirow{3}{*}{$\begin{array}{l}\text { Culture, } \\
\text { Ethics and } \\
\text { Behavior }\end{array}$} & $\begin{array}{l}\text { Between } \\
\text { groups }\end{array}$ & 15.244 & 2 & 7.622 & 6.962 & 0.001 \\
\hline & $\begin{array}{l}\text { Within } \\
\text { groups }\end{array}$ & 940.487 & 859 & 1.095 & & \\
\hline & Total & 955.731 & 861 & & & \\
\hline \multirow{2}{*}{$\begin{array}{l}\text { Services, } \\
\text { Infrastructure } \\
\text { and } \\
\text { Applications }\end{array}$} & $\begin{array}{l}\text { Between } \\
\text { groups }\end{array}$ & 0.566 & 2 & 0.283 & 0.378 & 0.686 \\
\hline & $\begin{array}{l}\text { Within } \\
\text { groups }\end{array}$ & 644.755 & 860 & 0.750 & & \\
\hline
\end{tabular}




\begin{tabular}{|l|l|l|l|l|l|l|}
\hline & Total & 645.321 & 862 & & & \\
\hline \multirow{4}{*}{$\begin{array}{l}\text { Organizational } \\
\text { Structures }\end{array}$} & $\begin{array}{l}\text { Between } \\
\text { groups }\end{array}$ & 5.691 & 2 & 2.846 & 2.777 & 0.063 \\
\cline { 2 - 7 } & $\begin{array}{l}\text { Within } \\
\text { groups }\end{array}$ & 880.222 & 859 & 1.025 & & \\
\cline { 2 - 7 } & Total & 885.913 & 861 & & & \\
\hline \multirow{5}{*}{ Processes } & $\begin{array}{l}\text { Between } \\
\text { groups }\end{array}$ & 7.638 & 2 & 3.819 & 4.631 & 0.010 \\
\cline { 2 - 7 } & $\begin{array}{l}\text { Within } \\
\text { groups }\end{array}$ & 709.171 & 860 & 0.825 & & \\
\hline & Total & 716.809 & 862 & & & \\
\hline
\end{tabular}

Table 7. Robust tests of equality of means (in case of significant Levene test)

\begin{tabular}{|l|l|l|l|l|}
\multicolumn{1}{c}{ Welch Statistic } & \multicolumn{1}{c|}{ Df1 Df2 } & \multicolumn{1}{c|}{ Sig. } \\
\hline Information & 3.195 & 2 & 163.111 & 0.044 \\
\hline $\begin{array}{l}\text { People, Skills and } \\
\text { Competencies }\end{array}$ & 1.075 & 2 & 162.129 & 0.344 \\
\hline
\end{tabular}

\subsubsection{Pairwise multiple comparisons}

The pairwise multiple comparisons for the COBIT 5 enablers that returned a significant result on the one-way ANOVA are displayed in the following tables (Table 8 to 11). As the Levene test for homogeneity of variances was significant for the information enabler and the people, skills and competencies enabler, Games-Howell post hoc tests were used for these two enablers. Significant results are shaded grey. The pairwise comparisons reveal that the ARC and IT group differ significantly in the assessment of the implementation of these four key enablers.

Table 8. Pairwise comparisons for "information" enabler (Games-Howell)

\begin{tabular}{|l|l|l|l|}
\multicolumn{1}{c}{$\begin{array}{c}\text { Group } \\
\text { Comparison }\end{array}$} & \multicolumn{1}{c}{$\begin{array}{c}\text { Mean } \\
\text { diff. }\end{array}$} & \multicolumn{1}{c|}{$\begin{array}{c}\text { Std. } \\
\text { Error }\end{array}$} & Sig. \\
\hline IT-Business & -0.111 & 0.124 & 0.643 \\
\hline IT-ARC & -0.160 & 0.063 & 0.032 \\
\hline Business-ARC & -0.049 & 0.122 & 0.916 \\
\hline
\end{tabular}

Table 9. Pairwise comparisons for "principles, policies and frameworks" enabler (Tukey HSD)

\begin{tabular}{|cccc|}
\hline Group & Mean & Std. & Sig. \\
Comparison & diff. & Error & \\
\hline
\end{tabular}

\begin{tabular}{|l|l|l|l|}
\hline IT-Business & -0.050 & 0.136 & 0.928 \\
\hline IT-ARC & -0.234 & 0.068 & 0.002 \\
\hline Business-ARC & -0.184 & 0.135 & 0.361 \\
\hline
\end{tabular}

Table 10. Pairwise comparisons for "culture, ethics

\begin{tabular}{|c|c|c|c|}
\hline $\begin{array}{c}\text { Group } \\
\text { Comparison }\end{array}$ & $\begin{array}{l}\text { Mean } \\
\text { diff. }\end{array}$ & $\begin{array}{l}\text { Std. } \\
\text { Error }\end{array}$ & Sig. \\
\hline IT-Business & -0.263 & 0.147 & 0.174 \\
\hline IT-ARC & -0.268 & 0.074 & 0.001 \\
\hline Business-ARC & -0.004 & 0.147 & 1.00 \\
\hline
\end{tabular}

Table 11. Pairwise comparisons for "processes" enabler (Tukey HSD)

\begin{tabular}{|l|c|c|c|}
\multicolumn{1}{c|}{$\begin{array}{c}\text { Group } \\
\text { Comparison }\end{array}$} & \multicolumn{1}{c}{$\begin{array}{c}\text { Mean } \\
\text { diff. }\end{array}$} & $\begin{array}{c}\text { Std. } \\
\text { Error }\end{array}$ & Sig. \\
\hline IT-Business & -0.035 & 0.129 & 0.961 \\
\hline IT-ARC & -0.192 & 0.064 & 0.008 \\
\hline Business-ARC & -0.157 & 0.128 & 0.961 \\
\hline
\end{tabular}

\subsection{COBIT 5 process domains}

\subsubsection{Descriptives}

Table 12 presents descriptive statistics for the five COBIT 5 process domains over the three functional roles.

Table 12. Descriptive statistics for COBIT 5 process domains over functional roles

\begin{tabular}{|c|c|c|c|c|c|c|c|c|}
\hline & & $\mathbf{N}$ & Mean & Std. Dev. & $\begin{array}{c}95 \% \text { CI } \\
\text { for mean } \\
\text { (lower) }\end{array}$ & $\begin{array}{c}95 \% \mathrm{CI} \\
\text { for mean } \\
\text { (upper) }\end{array}$ & Min & Max \\
\hline \multirow[t]{4}{*}{ EDM } & Business & 59 & 3.3119 & 0.94779 & 3.0649 & 3.5589 & 1 & 5 \\
\hline & IT & 389 & 3.0051 & 0.94805 & 2.9105 & 3.0996 & 1 & 5 \\
\hline & ARC & 411 & 3.2229 & 0.93011 & 3.1327 & 3.3131 & 1 & 5 \\
\hline & Total & 859 & 3.1303 & 0.94555 & 3.0670 & 3.1937 & 1 & 5 \\
\hline APO & Business & 59 & 3.5158 & 0.83283 & 3.2988 & 3.7329 & 1 & 5 \\
\hline
\end{tabular}




\begin{tabular}{|l|l|l|l|l|l|l|l|l|}
\hline \multirow{5}{*}{ BAI } & IT & 392 & 3.3853 & 0.81334 & 3.3046 & 3.4661 & 1 & 5 \\
\cline { 2 - 9 } & ARC & 411 & 3.5335 & 0.80524 & 3.4554 & 3.6116 & 1 & 5 \\
\cline { 2 - 9 } & Total & 862 & 3.4649 & 0.81315 & 3.4105 & 3.5193 & 1 & 5 \\
\cline { 2 - 9 } & Business & 59 & 3.4461 & 0.89331 & 3.2133 & 3.6789 & 1 & 5 \\
\cline { 2 - 9 } & IT & 390 & 3.2848 & 0.85978 & 3.1992 & 3.3704 & 1 & 5 \\
\cline { 2 - 9 } & ARC & 410 & 3.4938 & 0.84537 & 3.4117 & 3.5759 & 1 & 5 \\
\cline { 2 - 9 } & Total & 859 & 3.3956 & 0.86031 & 3.3380 & 3.4532 & 1 & 5 \\
\cline { 2 - 9 } & Business & 59 & 3.6503 & 0.92865 & 3.4083 & 3.8923 & 1 & 5 \\
\cline { 2 - 9 } & IT & 387 & 3.5938 & 0.85139 & 3.5087 & 3.6788 & 1 & 5 \\
\cline { 2 - 9 } & ARC & 410 & 3.7061 & 0.81567 & 3.6269 & 3.7852 & 1 & 5 \\
\cline { 2 - 9 } & Total & 856 & 3.6514 & 0.84080 & 3.5950 & 3.7078 & 1 & 5 \\
& Business & 59 & 3.4520 & 1.14431 & 3.1538 & 3.7502 & 1 & 5 \\
\cline { 2 - 9 } & IT & 383 & 3.2289 & 1.04896 & 3.1235 & 3.3343 & 1 & 5 \\
\cline { 2 - 8 } & ARC & 407 & 3.5287 & 0.98393 & 3.4328 & 3.6245 & 1 & 5 \\
\cline { 2 - 8 } & Total & 849 & 3.3881 & 1.03438 & 3.3184 & 3.4578 & 1 & 5 \\
\hline
\end{tabular}

\subsubsection{One-way ANOVA}

In this second stage, we test the null hypothesis of equal perceived implementation level between the three stakeholder groups at the level of the five COBIT
5 process domains. These results are displayed in Table 11. Significant results are shaded grey. As the Levene test for homogeneity of variances was insignificant for all process domains, robust tests of equality of means are not used in this stage.

Table 13. One-way ANOVA results for COBIT 5 process domains (significance level of 0.05 )

\begin{tabular}{|c|c|c|c|c|c|c|}
\hline & & $\begin{array}{c}\text { Sum o } \\
\text { Square }\end{array}$ & df & $\begin{array}{l}\text { Mean } \\
\text { Square }\end{array}$ & $\mathbf{F}$ & Sig. \\
\hline \multirow[t]{3}{*}{ EDM } & $\begin{array}{l}\text { Between } \\
\text { groups }\end{array}$ & 11.569 & 2 & 5.784 & 6.554 & 0.001 \\
\hline & $\begin{array}{l}\text { Within } \\
\text { groups }\end{array}$ & 755.531 & 856 & 0.883 & & \\
\hline & Total & 767.100 & 858 & & & \\
\hline \multirow[t]{3}{*}{ APO } & $\begin{array}{l}\text { Between } \\
\text { groups }\end{array}$ & 4.570 & 2 & 2.285 & 3.476 & 0.031 \\
\hline & $\begin{array}{l}\text { Within } \\
\text { groups }\end{array}$ & 564.733 & 859 & 0.657 & & \\
\hline & Total & 569.303 & 861 & & & \\
\hline \multirow[t]{3}{*}{ BAI } & $\begin{array}{l}\text { Between } \\
\text { groups }\end{array}$ & 8.895 & 2 & 4.448 & 6.080 & 0.002 \\
\hline & $\begin{array}{l}\text { Within } \\
\text { groups }\end{array}$ & 626.133 & 856 & 0.731 & & \\
\hline & Total & 635.028 & 858 & & & \\
\hline \multirow[t]{3}{*}{ DSS } & $\begin{array}{l}\text { Between } \\
\text { groups }\end{array}$ & 2.511 & 2 & 1.255 & 1.779 & 0.169 \\
\hline & $\begin{array}{l}\text { Within } \\
\text { groups }\end{array}$ & 601.933 & 853 & 0.706 & & \\
\hline & Total & 604.444 & 855 & & & \\
\hline \multirow[t]{3}{*}{ MEA } & $\begin{array}{l}\text { Between } \\
\text { groups }\end{array}$ & 17.990 & 2 & 8.995 & 8.557 & 0.000 \\
\hline & $\begin{array}{l}\text { Within } \\
\text { groups }\end{array}$ & 889.324 & 846 & 1.051 & & \\
\hline & Total & 907.314 & 848 & & & \\
\hline
\end{tabular}




\subsubsection{Pairwise multiple comparisons}

The pairwise multiple comparisons for the COBIT 5 process domains that returned a significant result on the one-way ANOVA are displayed in the following tables (Table 12 to 15). As the Levene test for homogeneity of variances was insignificant for all process domains, all post hoc tests are based on Tukey's HSD. Significant results are shaded grey. Consistent with the enabler results, these pairwise comparisons also suggest that the IT and ARC group differ significantly when assessing the implementation level of these four process enabler domains.

Table 14. Pairwise comparisons for EDM domain

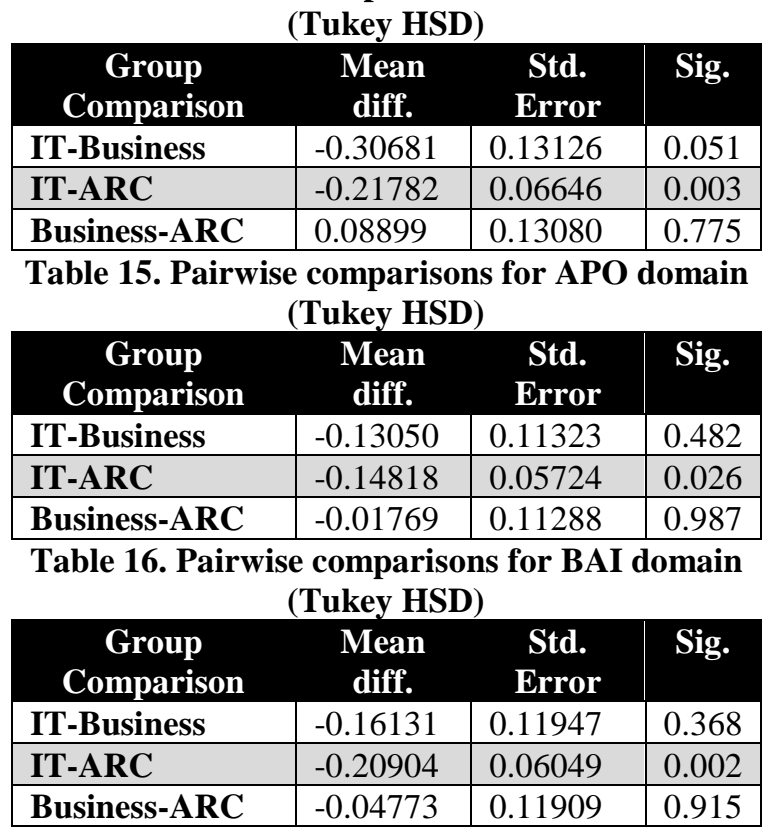

Table 17. Pairwise comparisons for MEA domain

\begin{tabular}{|c|c|c|c|}
\hline $\begin{array}{c}\text { Group } \\
\text { Comparison }\end{array}$ & $\begin{array}{l}\text { Mean } \\
\text { diff. }\end{array}$ & $\begin{array}{c}\text { Std. } \\
\text { Error }\end{array}$ & Sig. \\
\hline IT-Business & -0.22308 & 0.14339 & 0.266 \\
\hline IT-ARC & -0.29977 & 0.07299 & $0.000^{3}$ \\
\hline Business-ARC & -0.07669 & 0.14283 & 0.853 \\
\hline
\end{tabular}

\subsection{Discussion}

In the first stage of this research, we tested for the influence of functional role on the perceived implementation level of the seven COBIT 5 enablers. We found that four out of seven enablers showed significant differences in mean perceived implementation score. Post hoc tests revealed that differences existed for each of these four enablers between (1) the IT stakeholders and (2) the audit, risk, and compliance stakeholders. It appears that the IT stakeholders significantly perceive the implementation level of these four enablers to be lower compared to the audit, risk, and compliance stakeholders. The plausible explanation can be attributed to the fact that the significantly different assessed enablers cover a broad scope and concepts. For instance, the culture, ethics and behavior enabler can constitute a very distinct set of norms from the point of view of the IT stakeholders when compared to the ARC group. Moreover, such an enabler is always challenging to comprehend, codify, and communicate seamlessly across different stakeholders, who represent different cognitive skills and functional competencies. In this view, the IT group might have a high perceived understanding about the desirable behavior in the use and functionality of IT systems; however, their understanding might be limited on the topic of the compliance and regulatory issues. To this end, the ARC group is more accustomed to such issues and topics. Such plausibility can also be observed for (1) the principles, policies and frameworks, and (2) information enablers. Interestingly, we do not find any significant difference among the three groups on the assessment of enablers like (1) organizational structures and (2) services, infrastructure and applications. This outcome further reinforces the observation that enablers, which are more perceptible, have a very robust shared understanding among the three groups.

In the second stage of this research, we tested for the influence of functional role on the perceived implementation level of the five COBIT 5 process domains. We found that four out of five process domains showed significant differences in mean perceived implementation score. Entirely in line with the overall enabler results, post hoc tests revealed that differences existed for each of these four process domains between (1) IT stakeholders and (2) audit, risk, and compliance stakeholders only. In these cases, the IT stakeholders also significantly perceived the implementation level of these four process domains to be lower compared to the audit, risk, and compliance stakeholders. To this end, it is essential to acknowledge that the IT governance framework employed in this study, COBIT, has stronger historical linkage to the audit and control area. Moreover, the process enabler is the most advanced and well documented enabler in COBIT 5, which was rigorously used for IT audit assignments for many

\footnotetext{
${ }^{3}$ Significance of 0.000 means $<0.0005$
} 
years. In this view, the ARC can be argued to have sound background when assessing the process enabler, compared to a more limited background of the IT and business functions. This actually provides the ARC function somewhat of an upper hand in understanding the process enabler (and perhaps the overall COBIT framework) better than IT and business functions. Although, the latest edition of COBIT, COBIT 5, has a holistic approach by accommodating several best practices, standards, and frameworks; yet, business and IT functions warrant some 'sufficient time' for so called social alignment of IT governance.

Furthermore, business should be in the drivers' seat when it comes to enterprise governance and management of IT. They are the ones that should take up accountability, as business value from IT investments can only be created at the business side [1]. The audit, risk, and compliance stakeholders are the ones that are auditing these governance and management processes. In a way, it would not be surprising to find that these stakeholders would value the implementation status to be lower than the other stakeholders, due to their critical nature. Nevertheless, our results indicate that the IT stakeholders systematically and significantly value the implementation status of the COBIT 5 enablers and process domains to be lower than the audit, risk, and compliance stakeholders.

\subsection{Conclusions}

This paper provided exploratory insights in the effect of functional role on perceived IT governance implementation status. It did so by examining the perceptions of three different stakeholder groups (i.e. (1) business, (2) IT, and (3) audit, risk, and compliance) on the implementation status of the COBIT 5 enablers and the COBIT 5 process domains. This way, we aimed to better understand the "what" of shared understanding between these three stakeholder groups in the realm of enterprise governance and management of IT.

Following our results, we conclude that there is a lack of shared understanding about the implementation level of IT governance, especially between the IT and the ARC stakeholders. For the COBIT 5 enablers as well as the COBIT 5 process domains, the IT stakeholders significantly perceived the implementation status to be lower compared to the audit, risk, and compliance stakeholders.

\section{Implications (for theory and practice)}

From an academic point of view, this study shed an exploratory light on the issue of shared understanding between three relevant internal stakeholder groups in the area of enterprise governance and management of IT. Seeing that significant differences in perceptions were found, future research into the what, how, and why of perception differences in IT governance implementation status between different internal stakeholder groups is needed.

For practice, this study indicates that shared understanding between different internal stakeholders can be improved, especially between (1) IT and (2) audit, risk, and compliance stakeholders. Organizations can determine what their specific situation is regarding these issues, and take action to improve the situation when deemed necessary for their organization. Similar to the process enabler, which is already well-documented, this study warrants a more extensive publication of the other COBIT 5 enablers. This can indeed enhance the shared understanding of various stakeholders by providing more robust set of reference documents.

\section{Limitations and opportunities for future research}

A first clear limitation is that this study makes use of perception data. Therefore, this study provides no insight in the real situation of the IT governance implementation level, and which stakeholder groups are better at identifying the real status. Second, we have a relatively smaller representation of the business function in our sample. Acknowledging that a balanced sample (in terms of stakeholder groups) maximizes the power of the post hoc tests, we acknowledge that in our study the power of comparing the business group to IT or ARC is lower than when we compare IT to ARC. Lastly, this study only sheds light on the "what". It would be very interesting to study the "how" and "why" more in-depth, e.g. through case studies. This way, the dynamics leading to shared understanding in the area of enterprise governance and management of IT could also be studied.

\section{References}

[1] S. De Haes and W. Van Grembergen, Enterprise governance of information technology, second edition. Springer, 2015.

[2] S. De Haes and W. Van Grembergen, “An 
Exploratory Study into IT Governance Implementations and its Impact on Business/IT Alignment,” Inf. Syst. Manag., vol. 26, no. 2, pp. 123-137, Apr. 2009.

[3] P. Weill and J. W. Ross, IT Governance: How Top Performers Manage IT Decision Rights for Superior Results. Harvard Business Press, 2004.

[4] S. Ali and P. Green, "Effective information technology (IT) governance mechanisms: An IT outsourcing perspective,” Inf. Syst. Front., vol. 14, no. 2, pp. 179-193, Jun. 2009.

[5] R. Huang, R. W. Zmud, and R. L. Price, "Influencing the effectiveness of IT governance practices through steering committees and communication policies,” Eur. J. Inf. Syst., vol. 19, no. 3, pp. 288-302, Mar. 2010.

[6] R. R. Peterson, "Crafting Information Technology Governance,” Inf. Syst. Manag., vol. 21, no. 4, pp. 7-22, Sep. 2004.

[7] A. Prasad, P. Green, and J. Heales, “On IT governance structures and their effectiveness in collaborative organizational structures,” Int. J. Account. Inf. Syst., vol. 13, no. 3, pp. 199-220, Sep. 2012.

[8] J. C. Henderson and N. Venkatraman, "Strategic alignment: leveraging information technology for transforming organizations,” IBM Syst. J., vol. 32, no. 1, pp. 4-16, Jan. 1993.

[9] B. Reich and I. Benbasat, "Factors That Influence the Social Dimensions of Alignment Between Business and Information Technology Objectives,” Management Information Systems Quarterly, vol. 24, no. 1. 2000.

[10] D. S. Preston and E. Karahanna, "Antecedents of IS Strategic Alignment: A Nomological Network," Inf. Syst. Res., vol. 20, no. 2, pp. 159-179, Jun. 2009.

[11] P. L. Bowen, M.-Y. D. Cheung, and F. H. Rohde, "Enhancing IT governance practices: A model and case study of an organization's efforts,” Int. $J$. Account. Inf. Syst., vol. 8, no. 3, pp. 191-221, 2007.

[12] J. Day, "Strangers on the train," Inf. Technol. People, vol. 20, no. 1, pp. 6-31, Mar. 2007.

[13] G. Ray, W. A. Muhanna, and J. B. Barney, "Competing with IT: The Role of Shared ITBusiness Understanding," Commun. ACM, vol. 50, no. 12, pp. 87-91, Dec. 2007.

[14] W. Van Grembergen and S. De Haes, Enterprise Governance of Information Technology: Achieving Strategic Alignment and Value. Springer, 2009.

[15] S. P.-J. Wu, D. W. Straub, and T.-P. Liang, "How information technology governance mechanisms and strategic alignment influence organizational performance: insights from a matched survey of business and IT managers,” MIS Q., vol. 39, no. 2, 2015.

[16] P. Zhang, K. Zhao, and R. L. Kumar, "Impact of IT Governance and IT Capability on Firm Performance,” Inf. Syst. Manag., vol. 33, no. 4, pp. 357-373, Oct. 2016.

[17] G. L. Lunardi, J. L. Becker, A. C. G. Maçada, and P. C. Dolci, "The impact of adopting IT governance on financial performance: An empirical analysis among Brazilian firms," Int. $J$. Account. Inf. Syst., vol. 15, no. 1, pp. 66-81, 2014.

[18] S. De Haes, W. Van Grembergen, and R. S. Debreceny, "COBIT 5 and Enterprise Governance of Information Technology: Building Blocks and Research Opportunities,” J. Inf. Syst., vol. 27, no. 1, pp. 307-324, Jun. 2013.

[19] ISACA, “COBIT 5: A Business Framework for the Governance and Management of Enterprise IT,” 2012.

[20] D. Chatterjee, V. J. Richardson, and R. W. Zmud, "Examining the Shareholder Wealth Effects of Announcements of Newly Created CIO Positions," MIS Q., vol. 25, no. 1, p. 43, Mar. 2001. 